Historic, Archive Document

Do not assume content reflects current scientific knowledge, policies, or practices. 


\section{Suggestions on Seed Sowing}

Copyright, 1920 (ALL RIGHTS RESERVED) BY

W. Atlee burpee Co., Seed Growers, Philadelphia, Pa., U. S. A.

Mistakes are often made in the sowing of seed which cause partial or complete failures. As a consequence the seed is sometimes blamed when the failure is really due to the disregard of a few fundamental principles of sowing. There are four requirements for good germination of seed:

\section{Viability (Life in the Seed). 2. Moisture. 3. Air. 4. Heat.}

The production of good and true seed is the responsibility of the seedsman. In producing Burpee-Quality seed the aim has always been to do away with all uncertainties. Every lot of Burpee's Seeds is tested both for viability and type before being sent out. This entails tremendous expense and a great amount of trouble, but it accounts for the quality reputation which Burpee's Seeds enjoy wherever planting is done.

Moisture is more or less readily absorbed by the seed and causes swelling. The time in which this swelling takes place varies considerably. Some seeds absorb sufficient moisture in a day or two, while others with hard shells will sometimes be in the ground for a month or longer before germinating. As a chemical moisture acts upon certain substances in the seed which dissolve and are rebuilt into other forms, to serve as food for the plant. After this chemical stage comes the live stage of the plant, or the multiplication of p'ant cells, that is, "the seeds grow." The first two changes will take place in seeds devoid of life, but the third depends altogether on its presence.

The oxygen of the air enters into the chemical changes which take place in the seeding.

$\mathrm{Heat}$, the fourth requirement, varies greatly as to the degree needed by different sorts of seed. Seeds are $d$ vided generally into three classes: The cool weather or hardy plants requiring from 50 to 70 degrees Fahrenheit for germination; a second class, the half-hardy plants, requiring from 60 to 80 degrees; and tropical or hot-house seeds, which will not germinate unless the surrounding temperature is from 75 to 90 degrees.

\section{How to Assist Germination}

From the foregoing one will see that unless certain conditions are present, seeds will not grow. It is up to the gardener to assist in the germination as much as possible by bringing about these conditions. We generally do aid by preparing the seed-bed, by watering, by protecting, etc., but there are other means of assisting germination when seeds will not respond to the usual treatment.

First, certain seeds with very hard coats or shells around the germ, such as Cannas, Moonflowers, Cardinal Climber, Ipomœas, and others, require a long time for the water to penetrate the hard shells. We can hasten absorption by placing these seeds in a tumbler of luke-warm water and letting them soak from twelve to twenty-four hours or even longer until they have swollen up. Another means is the clipping of a portion of the hard coat. This is done with a sharp knife, cutting away a very small part of the shell, and taking care not to injure the interior of the seed. A file will answer the same purpose as a knife. Of course, this method is not practical on large plantings, but is useful chiefly to the amateur. Some field seeds, particularly clover, are sometimes run through a machine for the purpose of scarring the hard outer coat. This process is known as "scarifying." It results in quicker and more complete germination if it is done just before the seed is sown, but the results are hardly worth the extra trouble.

In all cases the handling of treated seeds is more difficult than when the seeds are sown without special treatment. After seeds have once absorbed moisture, they must under no circumstances be allowed to dry out again. Swollen seeds must be planted with care and just slightly pressed into the soil to avoid crushing the germ. 
Another method of encouraging quicker germination is to apply boiling water to the seedbed immediately after sowing.

\section{Depth to Sow}

One of the most important factors in successful sowing is the depth at which the seeds are placed in the soil. Very small seeds should be pressed into the surface or barely covered from view. As a general rule, seeds should be sown at a depth equal to three times their diameter. The depth to sow depends also on the character of the soil. In light, sandy soils seeds may be sown more deeply, as the young sprouts will not require such force to push up to the surface. Another factor determining the depth is the weather conditions. During warm weather, with little rainfall, we must sow deeper to bring the seeds in contact with the moisture in the soil. During wet weather seeds should be sown less deeply. As a rule, we can expect more rain in springtime than during the summer; consequently spring-sown seeds should not be covered as deeply as those sown during summer or fall.

The character of the seedling is also important with the larger seeds, such as beans, peas, and corn. Consider, for example, beans in which the cotyledons or seed-leaves push through the soil in the form of a hook-like shoot. Here we have quite a quantity of tender growth which must break its way to the surface. One will readily see that corn, with its spear-like shoots, could be planted deeper and would, nevertheless, push through more easily. Peas require more force to get to the surface than corn, but less than beans, as they do not push up with the seedleaves as beans do. Corn can force its way up from a surprising depth, whereas beans, and limas particularly, should not be placed deeper than $2 \frac{1}{2}$ inches, or they may not come up at all. By the way, do you know the old gardener's secret of getting a good stand of lima beans? They should always be planted with the "eye" down.

\section{Time to Sow}

The time to sow seeds depends on the character of the seed, as well as on the weather. Hardy plants which are native to sections having severe winters may be sown just as soon as the frost is out of the ground and the soil can be prepared. Half-hardy seeds cannot stand as severe conditions and are sown after all danger of freezing has passed. Tender plants, such as Balsam, Begonia, Heliotrope, Coleus, and Ricinus, also Lima Beans, Melons, Cucumbers, etc., which came to us from subtropical or tropical climates, cannot be sown until the time when the trees are well out in leaf and the ground has become warmed up. Possibly we should mention the old belief in the effect of the phases of the moon on planting, but, frankly, we have never found that the moon had any influence that we could see on the germination of the seed or on gardening operations generally.

\section{Preparations for Indoor Sowing}

By sowing indoors we can raise tender plants in sections where they could not otherwise be grown. By sowing into specially prepared containers, under conditions favorable to germination, we can have good-sized plants long before outdoor conditions would warrant a start in the open.

The amateur will find it of value to know how to make a seed flat. A seed flat is a box of ' handy size, say twelve by fifteen inches and three or four inches deep, made of fairly heavy wood and well put together. The bottom should be perforated with holes about a quarter of an inch in diameter, placed one to every twenty-five square inches of bottom space to carry off surplus water.

For indoor sowing a special soil should be prepared. Bear in mind that a most important factor in satisfactory germination of seeds is suitable soil. A good standard mixture is five parts of good garden loam, one part of fine sand, one part of finely chopped, well-rotted manure, and just a little lime-say a cupful to a bushel of soil. All these ingredients should be shaken through a fine sieve and then thoroughly mixed. If too dry, water should be sprinkled over the pile while mixing the soil.

In filling the seed flat ordinary garden soil may be placed in the bottom, with an inch or two of this specially prepared compost soil on the top. To prevent the soil from being carried 
away through the drainage holes a small stone or piece of crock should be placed over each hole. After the ordinary soil has been poured in it should be leveled off and then pressed down with a smooth board. The compost soil is then filled in to above the brim, and the flat knocked upon a firm table to settle the soil into a natural position. Then sweep off any soil standing above the brim with a board and press it against the surface to make it perfectly smooth. The flat is now ready for sowing.

\section{Sowing in the Seed Flat}

Fine seeds should be sprinkled broadcast over the surface and merely pressed into the soil with a board. Larger seeds, such as Cabbage and Tomatoes, may be sown in shallow rows an inch or two apart, pressed into the soil, and covered to a depth of twice their diameter with fine soil. Press the surface down smooth and water with as fine a spray as possible, or set the flat in a pan or sink containing about two inches of water until it soaks up through the holes in the bottom to the surface.

A pane of glass placed on top of the flat will serve to prevent undue evaporation and hold the warmth. Whenever large drops gather on the under side of the glass they should be wiped off and the glass raised for the remainder of the day to allow some evaporation.

The location of the seed flat is important. A sunny window will be most suitable, but the flat should be shaded from the hot midday sun. Seedlings and growing plants must be kept in a room where fresh air can circulate.

As soon as the sprouts break through the soil the pane of glass must be removed. Ordinarily no further watering will be necessary until the plants have been up for a day or two. Water the plants only when they need it, but then water carefully and thoroughly. Many failures are due to watering too frequently, not giving enough each time.

Another appliance, which has been termed "Grandmother's," should be more generally known. An ordinary brick is placed in a low pan containing enough water to reach about halfway up the side of the brick. On top of the brick is placed a layer of very fine garden soil, about an inch or an inch and a half deep, pressing the soil fairly firm. The edges of the dirt on top of the brick should be somewhat slanted to prevent crumbling. Sow the seed on top of this soil. An even amount of moisture will be drawn up through the brick and soil to the seeds so that no other watering will be required. Of course it is necessary that the water in the pan be kept. at its original level. If at any time the soil seems too wet, take the brick out of the water for a few hours. This method is an easy one and a good one, especially for starting very fine and slowly germinating seeds.

\section{Transplanting}

As soon as the plants can be handled-in most cases this will be when they are one-quarter to one-half inch high - they are ready for transplanting. If they come up too thickly, all the plants may be lost even before they are half an inch high, due to "damping off." This is caused by a minute fungus which develops most freely when too much moisture is given and free air circulation is hindered. Transplanting the seedlings will generally save those which have not yet been affected by the fungus. When transplanting, the soil around the plants should be loosened up from the side, so that each plant can be removed with all its roots intact.

The transplanting flat is prepared in the same way as the seed flat. Lift the plants carefully and set them in the holes, which must be deep enough to take in all the roots. Plants measuring up to one inch high will be found to have plenty of space for a time, if set two inches apart. When the flat is filled, smooth the soil, and then water with a fine spray. The flat should now be placed in the shade until the roots have taken a good hold. As the plants grow, they should be exposed and hardened very gradually to outdoor conditions.

\section{The Seed Bed in the Open}

Certain plants require special care as seedlings, but do not need to be started until the weather permits outdoor sowing. The outdoor seed-bed is used as a nursery for late Cabbage, late Cauliflower, late Tomatoes, etc., and to a large extent for perennial flowers.

It should be sheltered from the north against the hot midday sun. The soil should be loamy, well drained, and free from harmful insects. The finer the top layer, the better chance 
the seeds will have to germinate properly. Nake it perfectly even and smooth, and, if possible, mix in a quantity of sand and well-rotted manure. Then sow the seed either broadcast or in shallow drills, covering them to a depth equal to twice their diameter with mellow and fine garden soil. As the seedlings begin to crowd each other they should be transplanted to their permanen/place.

\section{Sowing in the Garden}

The majority of the common vegetable and flower seeds may be sown in the place where the plants are to remain all season. A medium heavy loam with a good admixture of sand will prove most favorable to perfect germination of the seed.

The preparation of the soil consists in thoroughly plowing or spading six to eight inches deep and afterward working the surface with a rake to make it as fine as possible. Of course, all large stones and coarse material should be raked out. Most seeds are sown in furrows. On ground containing excessive moisture the seeds may be sown on top of hills about three or four inches high, made by drawing the soil together with the hoe.

For the small home gardener hand sowing is the only consideration, but in the extensive plantings of the market gardener the various types of seed drills will save time and labor. Sowing seeds by hand requires a certain skill which one will acquire by practice. It is important that the seeds be sown thinly. The depth to sow depends on the size of the seed, the ty pe of the soil, the time of the year, the weather, and the mode of germination. On the average, in outdoor plantings, seeds should be covered to a depth of thrice their diameter. In il cases cover with fine soil, free from stones or other coarse material, and press the top soil il to close contact with the seed, using the back of the hoe or rake. If the weather is dry, apply fater. A fine spray must be used, as otherwise the seeds may be washed out of the ground. Germination may be hastened by covering the rows with cheese-cloth or paper, held in place by stones, to retain the heat and moisture. In the case of Cucumbers and Melons, which are usually planted in hills, also Peppers, Egg Plants, and Tomatoes, shallow boxes covered with cheese-cloth placed over the plants will stimulate early growth.

A most important factor in making a success of sowing is the thinning of the seedlings. Usually having the plants too thick is unavoidable, and there is a good reason why seeds should be sown thicker than they will have to stand, especially in heavy soils, as they will more easily break through the overlying soil. In thinning the plants be sure that the whole plant, top and root, is removed and not merely the top pinched out. Thin your plants, as soon as they can be handled, to stand one or two inches apart. Later on their distance is governed by the size the plants attain at the time of maturity. It is better to thin repeatedly at short intervals than to thin the plants all at once to the distance they will stand when mature. Then the plants which are injured by insects or storms will not cause gaps in the row.

But, after all is said and done, care, patience, and watchfulness must work hand in hand with knowledge, and perhaps the best advice we can give the gardener is to study his local conditions, observe and profit by the inevitable mistakes, and gradually attain that sympathy with nature and understanding of her methods sô that he will know, without being told, what his plants require.

This is one of a series of leaflets published for Free Distribution to planters of Burpee's Seeds. These leaflets are all practical, written by experts, and give the results of actual experience. We have accumulated in our forty odd years of planting experience a large amount of useful information which is always at your disposal. It is our aim to supply the Best Seeds that can be Grown and also to tell plainly the best methods of cultivation.

\section{W. Atlee Burpee Co. \\ Seed Growers Philadelphia}

Write for BURPEE'S ANNUAL, The Leading American Seed Catalog-Sent Free 